\title{
Decision making based on single and double acceptance sampling plans for assessing quality of lots
}

\author{
Ksenija Dumičić and Berislav Žmuk
}

Department of Statistics, Faculty of Economics and Business, University of Zagreb, Zagreb, Croatia

\section{Abstract}

Background: Acceptance sampling is a statistical tool of quality control. Sampling plans and operating characteristic (OC) curves are very useful for conducting acceptance sampling and provide the quality manager with tools to evaluate the quality of a production run or shipment. There are developed different sampling plans, but common used in practise are single and double acceptance sampling plans. Objectives: The goal of the paper is to test if applying of single and double sampling plan can lead to statistically significant different conclusion about quality level of observed lot. Methods/Approach: Statistical tests of difference in proportions are used to test if there is some statistically significant difference in probabilities of lot fraction defectives between a single and a double sampling plan at the same levels of probability of acceptance. Results: The results of the analysis show that in some cases there is statistically significant difference. Namely, the quality manager should be careful when he chooses to use, instead of the first, the second sampling plan with different parameters because on that way he could make statistically significant different conclusion about quality level of observed lot. Conclusions: The paper shows that some intentional manipulations by using different sampling plans are possible.

Keywords: lot, single acceptance sampling plan, double acceptance sampling plan, operating characteristic curve, supplier's and buyer's risk

JEL classification: C1, L15, M21

Paper type: Research article

Recieved: 29, November, 2011

Revised: 11, July, 2012

Accepted: 20, July, 2012

Citation: Dumičić, K., Žmuk, B. (2012). "Decision making based on single and double acceptance sampling plans for assessing quality of lots", Business Systems Research, Vol. 3, No. 2, pp. 27-40.

DOI: 10.2478/v10305-012-0010-4

\section{Introduction}

An acceptance sampling is one of three major statistical areas which are used for quality control and improvement. An acceptance sampling is a form of testing which involves taking random samples of lots and measuring them against predetermined standards. Depending on kind of production, a lot or a batch can contain one or, in majority cases, more than one raw material, component or final product.

The lot can be inspected immediately following production or before the product is shipped to the customer. From other side, the lots can be inspected as they are received from the supplier. In the first case it is conducted outgoing inspection and in the second case incoming inspection (Montgomery et al., $2011)$.

If a supplier's process provides no defective units and no economic justification to make an inspection exists, the lot is accepted without inspection. But when defective units might result in a considerably high failure costs for the buyers, or when it is known that a supplier's processes do not meet a certain level of quality standards, than is a $100 \%$ inspection recommended (Montgomery, 2009). An acceptance sampling is between those two approaches to the lot inspection and is used only when the samples of lots are inspected. On this way, an acceptance sampling can, in the same time, save resources and ensure that the output of a process confirms to requirements. An acceptance sampling is most useful to conduct 
when product testing is destructive, very expensive, very time consuming or when product liability risks are significant (Starbird, 1994).

Because of sampling, it could happen that the lot which has a satisfactory predetermined level of quality will be rejected and that the lot which does not have a satisfactory predetermined level of quality will be accepted. The first situation is known as supplier's risk or a, and the second situation is known as buyer's risk or B (Wadsworth et al., 2002).

There are a number of different ways to classify acceptance sampling plans. One of major classification is by variables and attributes (Montgomery et al., 2011). Variables are quality characteristics which are measured on a numerical scale, and attributes are quality characteristics which are expressed as binary result (e.g. a good-bad lot, go-no go). Acceptance sampling plans for attributes are easier to conduct than acceptance sampling plans for variables. Because of that, acceptance sampling plans for attributes are more common in practice and in this paper focus is on this type of acceptance sampling plans. There are different kinds of acceptance sampling plans for attributes: single, double, multiple, sequential and skip lot sampling plans (NIST/SEMATECH, 2003). Single and double acceptance sampling plans are most used in practice because they are simple to use, and so the main focus of this paper is on these kinds of acceptance sampling plans.

The aim of this paper is to investigate how usage of different acceptance sampling plans could lead to different conclusions and decisions about accepting or rejecting a lot. Both single and double sampling plans in different cases are considered and compared. Parameters for the sampling plans are changed to simulate possible results and conclusions of inspections. The sampling plans are compared at the same level of probability of acceptance. Inference is based on a statistical test for the difference in proportions. When the test shows that the difference is statistically significant, the producer's quality manager could lower quality costs easily by choosing one of the observed sampling plans. The producer's quality manager may choose to use the sampling plan which shows statistically smaller lot fraction of defective units. On that way, the customer could be misleading about the lot. The paper is emphasizing the probability of this fraud and investigates circumstances under which is this possible to do.

\section{Chosen sampling plans}

Because of wide and often usage, in the paper are considered single and double sampling plans for attributes only.

\section{Single sampling plan}

The simplest types of sampling plans are those which involve a single sample. Such sampling plan is single sampling plan for attributes. This plan is determined with two parameters. The first parameter is the number of random chosen units from the observed lot or $n$, and the second is the number of defective units which can be tolerated or $\mathrm{c}$. If the lot inspection finds more defective units in the lot than is allowed, the lot will be rejected. If the lot is rejected, there are some possible actions which can the customer undertake. The most rigorous action would be sending the lot back to the producer. But in most cases, next step action is inspecting all units in the lot and replacing defective units with good units. On the other hand, if the lot inspection finds $x$ defective units in the lot, where the $x$ is equal or smaller than $c$, the lot will be accepted. The way of making this decision is shown in Figure 1.

Figure 1

Decision Making in a Single Sampling Plan

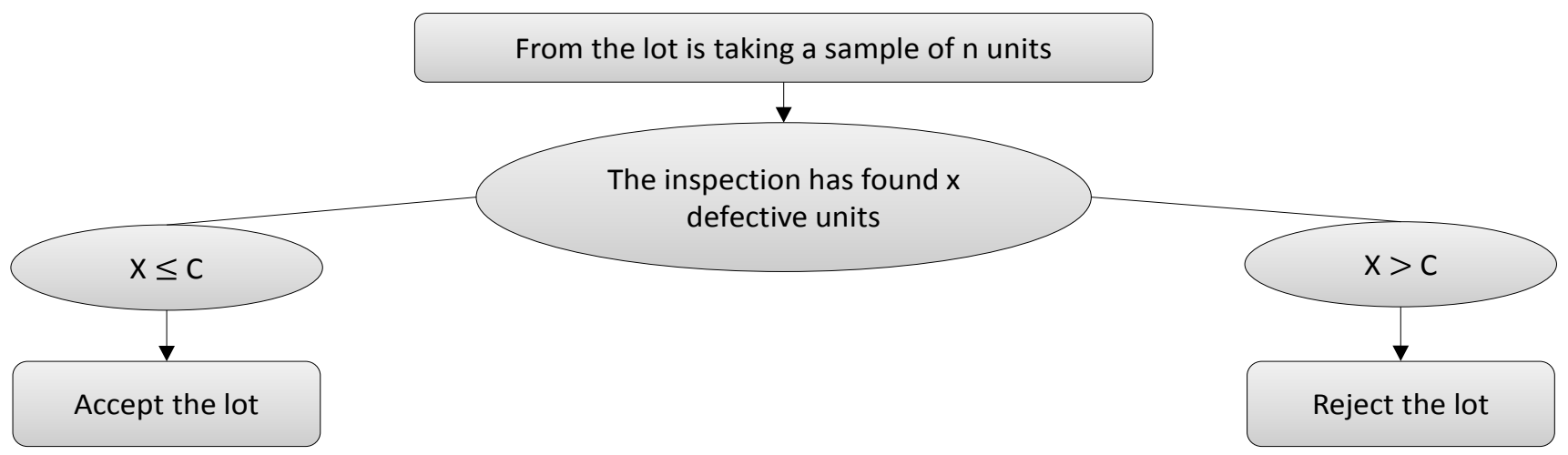

Source: Author's illustration 
An operating characteristic $(O C)$ curve is a graphical display of a sampling plan. It describes how well a sampling plan discriminates between good and bad lots (Dumičić, et al., 2006). Under good lots are meant lots which have satisfactory determined level of quality or lots in which the number of defective units is not greater than the maximum allowed number of defective units. Bad lots are such lots which should be rejected because they do not have expected level of quality. Each sampling plan has a unique OC curve. In Figure 2 is shown the general shape of the OC curve for a single sampling plan. The shape of the OC curve for a single sampling plan is determined with parameters $n$ and $c$.

Figure 2

The Operating Characteristic (OC) Curve of a Single Sampling Plan

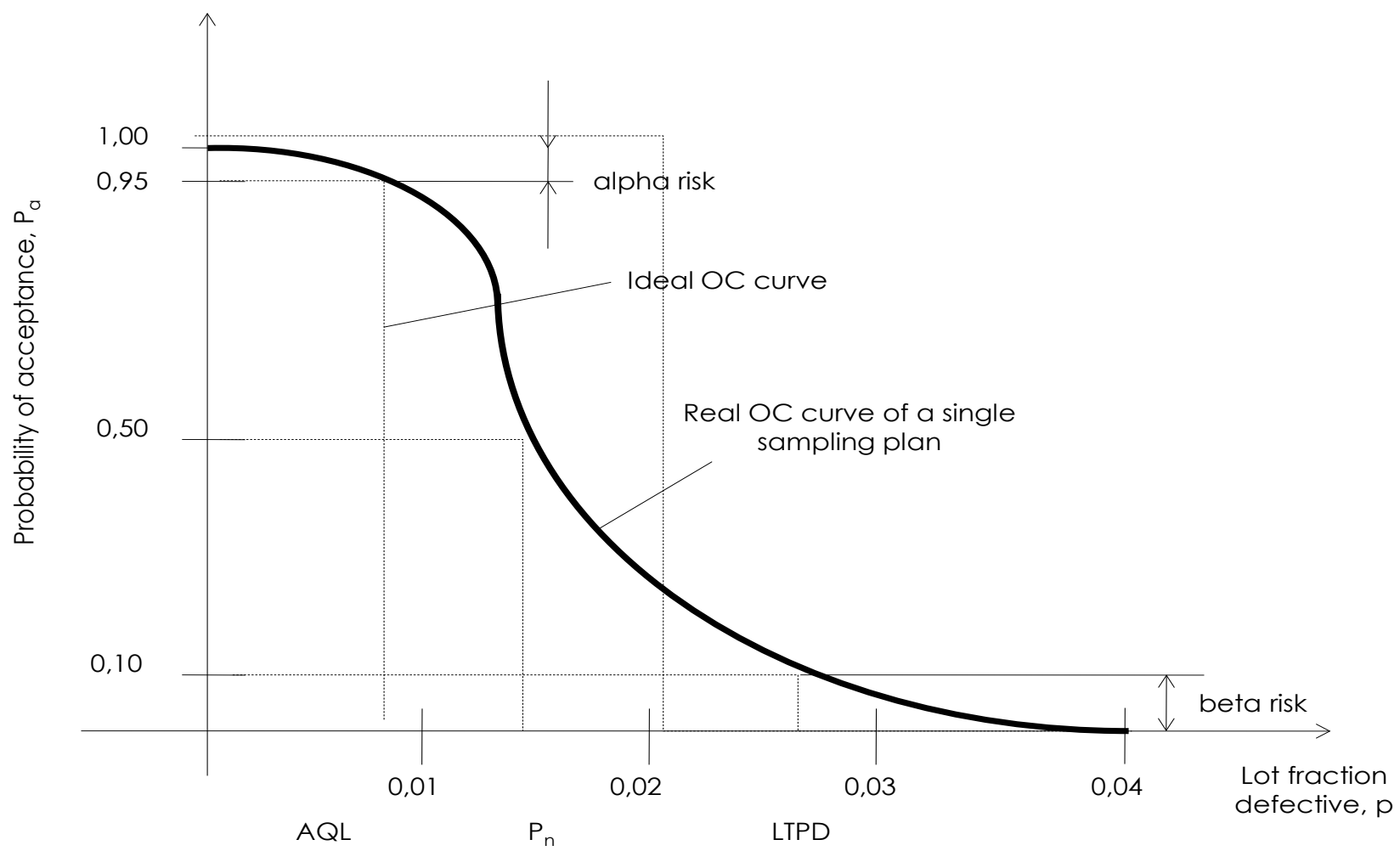

Source: Kondić, 2004, p. 480

The OC curve shows the probability that a lot, submitted with a certain fraction defective, will be either accepted, or rejected (Montgomery et al., 2011). On the x-axis are shown proportions (or probabilities) of defective units which are made in a certain process. These proportions are denoted as $p$ and represent the lot fraction of defective units. On the y-axis are shown probabilities of acceptance of a certain lot. These probabilities are denoted as Pa. In acceptance sampling units for an inspection are chosen randomly and without replacing from a finite population (a finite lot). So the proper way to compute probability of acceptance would be to use the hypergeometric distribution. But if the lot size is large relative to the sample size, the binomial distribution may be used. This approximation is quite satisfactory if the lot size is more than ten times the sample size (Wadsworth et al., 2002). In other words, if the lot size $\mathrm{N}$ is large enough to be declared as infinite, the distribution of the number of defectives $x$ in a random sample of $n$ units will be binomial with parameters $n$ and $p$. In this case, the probability of observing exactly $x$ defectives is:

$$
P\{x \text { defectives }\}=f(x)=\frac{n !}{x !(n-x) !} p^{x}(1-p)^{n-x}
$$

where $\mathrm{n}$ is the sample size or the number of chosen units for inspection, $\mathrm{x}$ is the number of founded defective units in the lot, $\mathrm{p}$ is lot fraction defective or assumed process probability to make a defective unit. From that, the probability of acceptance or probability that $x$ is less than or equal to $c$ is:

$$
P_{a}=P\{x \leq c\}=\sum_{x=0}^{c} \frac{n !}{x !(n-x) !} p^{x}(1-p)^{n-x}
$$


where $\mathrm{n}$ is the sample size or the number of chosen units for inspection, $\mathrm{x}$ is the number of founded defective units in the lot, $\mathrm{c}$ is maximum allowed number of defective units, $\mathrm{p}$ is lot fraction defective or assumed process probability to make a defective unit.

The OC curve contains three specific points which are shown in Figure 2. These points are the acceptable quality level (AQL), the lot tolerance percent defective (LTPD) and the neutral quality level (Pn). The AQL represents the poorest or minimum level of quality of supplier's process that the buyer would consider to be acceptable as a process average (Montgomery et al., 2011). The AQL is base for making a decision of accepting or rejecting the observed lot. Because of sampling, there always exists some probability of rejecting a lot. Even if the supplier's process ensures a smaller lot fraction defective than specified with AQL, this probability will exist. This probability is known as supplier's risk or a risk. There is always the probability that the buyer will accept a lot of poor quality, too. This probability is known as buyer's risk or B risk. From the other side, the LTPD is the minimum quality level that the buyer is willing to accept. Between the AQL and LTPD points there is an area of indifference. So, there in the point $\mathrm{Pn}$ is the neutral quality level. In this point the probability of acceptance and rejecting a lot is equal and it has value of 0.50 .

\section{Double sampling plan}

In contrast to a single sampling plan, a double sampling plan implies possibility of taking two independent samples of units from the lot. The second sample is formed only when it is necessary. In Figure 3 is shown the way of decision making in a double sampling plan.

Figure 3

Decision Making in a Double Sampling Plan

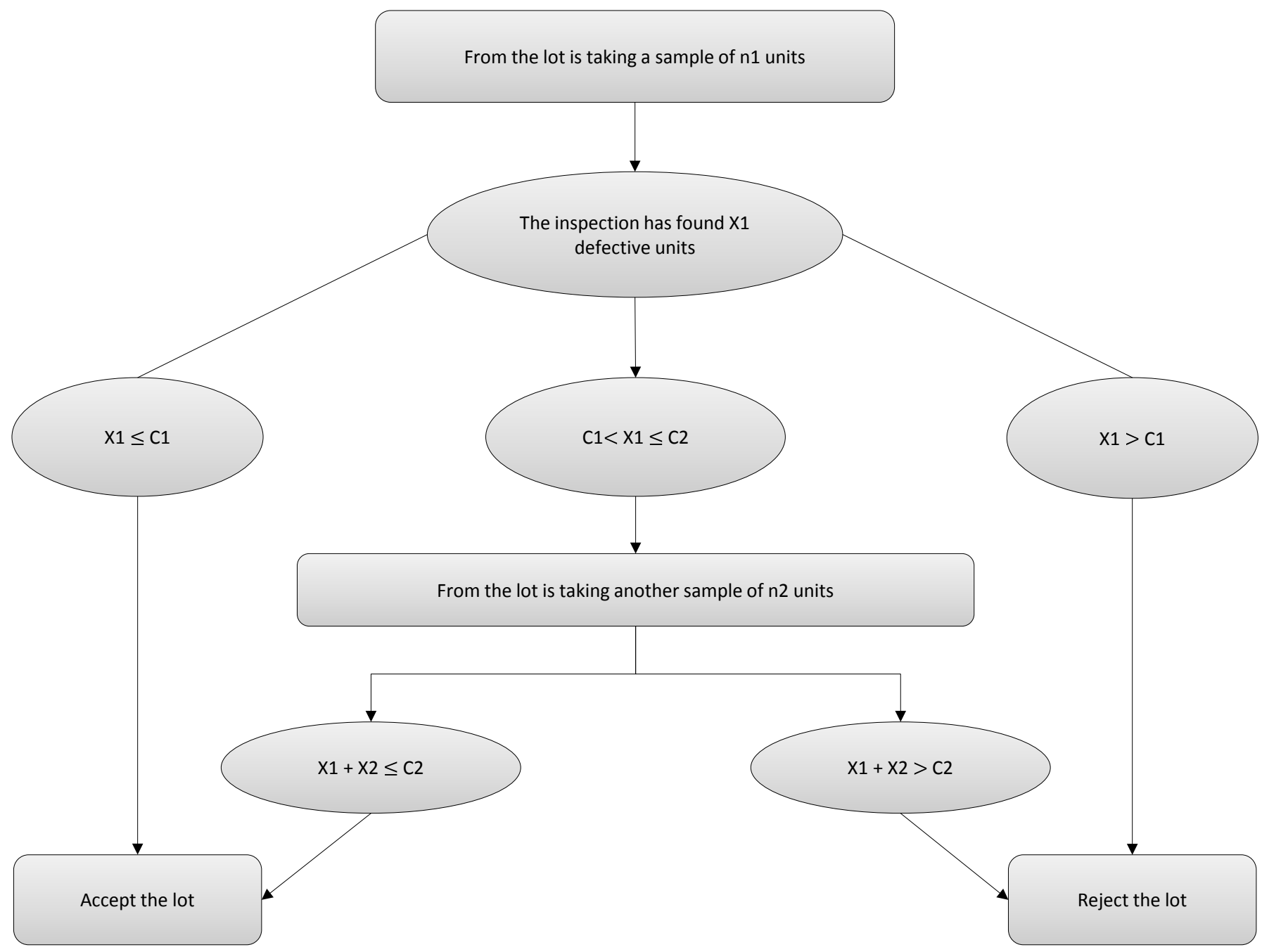

Source: Author's illustration 
Like in a single sampling plan, first are taken some units from observed lot for inspection. On that way in a double sampling plan is formed the first sample of $\mathrm{nl}$ units. Because of possibility that one more sample will be formed, the number of units in this sample is usually smaller than the number of units in the sample in a single sampling plan. If the sample size in a single sampling plan is equal to $\mathrm{n}$, it can be written $n>n_{1}$. This difference in sample sizes is a big advantage for a double sampling plan. Because of smaller initial sample size, a double sampling plan needs less resources to conduct it than a single sampling plan. It has to be emphasized that this advantage comes to expression only if is needed to chose just one sample to make a decision. In a double sampling plan there are set two limits of maximum allowed number of defective units. The first limit is denoted as $\mathrm{Cl}$ and is known as the acceptance level for the first sample. The second limit is denoted as $\mathrm{c} 2$ and is known as the acceptance level for both samples. The first limit is always smaller than the second. Usually is the second limit double bigger than the first one. If the number of defective units which have been found in the first sample is smaller or equal to the first limit, the lot will be accepted. But if the number of defective units which have been found in the first sample is greater than the second limit, the lot will be rejected. In Figure 4 are shown OC curves for these situations. The curve A shows the probability of acceptance on the first sample and is calculated as

$$
P_{a}^{A}=P_{a}^{I}=P\left\{x_{1} \leq c_{1}\right\}=\sum_{x_{1}=0}^{c_{1}} \frac{n_{1} !}{x_{1} !\left(n_{1}-x_{1}\right) !} p^{x_{1}}(1-p)^{n_{1}-x_{1}}
$$

The curve B describes the probability of not rejecting the lot on the first sample and is calculated as

$$
P_{a}^{B}=P\left\{x_{1} \leq c_{2}\right\}=\sum_{x_{1}=0}^{c_{2}} \frac{n_{1} !}{x_{1} !\left(n_{1}-x_{1}\right) !} p^{x_{1}}(1-p)^{n_{1}-x_{1}}
$$

The difference between the two curves is the probability of taking a second sample.

Figure 4

The Operating Characteristic (OC) Curve of a Double Sampling Plan

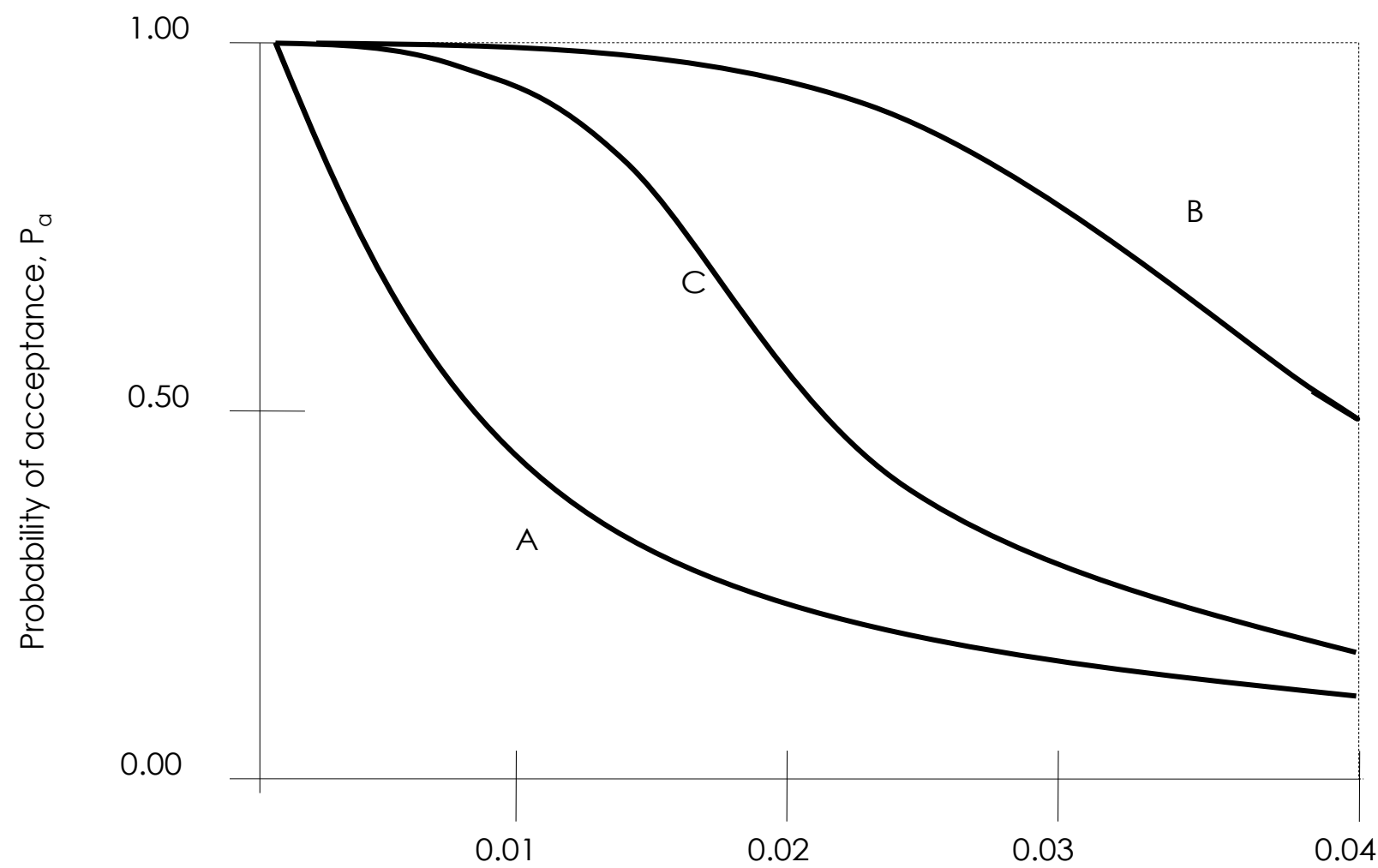

Lot fraction defective, $\mathrm{p}$

Source: Grant and Leavenworth, 1980, p. 376 
If the number of defective units found in the first sample is bigger than the first limit simple but not bigger than the second limit, a decision cannot be made. In this case, the second sample of n2 units from the lot has to be formed. Usually the second sample size is equal to the first sample size or is twice as the first. The number of founded defective units in the second sample, which is denoted as $x 2$, is added to the number of founded defective units in the first sample and then is compared to the second limit. If the overall number of defective units in both samples together is found to be equal to or smaller than the second limit, then the lot will be accepted. But if the overall number of defective units in both samples together is found to be bigger than the second limit, then the lot will be rejected. The OC curve which represents this situation is shown in Figure 4 and is denoted as curve $C$. The curve $C$ is the final curve and describes the probability of acceptance for the double sampling plan. It can be calculated as sum probabilities of acceptance on the first and second samples or as

$$
P_{a}=P_{a}^{I}+P_{a}^{I}=P\left\{x_{1} \leq c_{1}\right\}+\sum_{i=c_{1}+1}^{c_{2}} P\left\{x_{1}=i\right\} P\left\{x_{2} \leq c_{2}-i\right\}
$$

The probability of acceptance on the first sample $\left(P_{a}^{I}\right)$ includes probability for $x_{1} \leq c_{1}$ and the probability of acceptance on the second sample $\left(P_{a}^{I}\right)$ includes probability of different ways in which the second sample can be obtained (Dumičić, Žmuk, 2011).

\section{Data, methods and analysis}

\section{Data and methods}

Because of examining different possible situation in a practice, in this paper it will be used different sample sizes and maximum allowed numbers of defective units in a lot. On this way it will be possible to compare probabilities of acceptance and rejection of a lot between a single and a double sampling plan. Precisely, it will be tested if there is some statistically significant difference in probabilities of lot fraction defectives between these two sampling plans at the same levels of probability of acceptance. If there will be found a statistically significant difference, it would be interesting to identify conditions under which that happened. The existing of a statistically significant difference in probabilities of lot fraction defectives implies existing of statistically significant possibility of making different conclusion about a lot using a simple or a double sampling plan.

The OC curves will be used to identify probabilities of lot fraction defectives. Necessary calculations for construction the OC curves will be made in Excel 2007. Probabilities of lot fraction defectives will be observed at three values of probability of acceptance. These values of probability of acceptance are $0.10,0.50$ and 0.95. The first value represents the $B$ risk, the second equal probability of accepting and rejecting a lot, and the third value represents the a risk of $5 \%$. A conclusion about existence of any significant difference between the compared lot fraction defectives in a single versus a double sampling plan at these selected probabilities of acceptance is reached using the test for differences in the two proportions.

It is assumed that the observed lot contains a large number of a certain product. On this way it is ensured that the selected samples size will contain relatively small number of units so the binomial distribution can be used. Next assumption is that the quality manager considers using a single or a double sampling plan for conducting inspection of the lot. In a single sampling plan parameter $\mathrm{n}$ is going to be set at 100, 200 and 300 units. The second parameter in a single sampling plan or $\mathrm{C}$ is going to be set at $0,2,4,6,8$ and 10. A double sampling plan is defined with four parameters. As values of the first sample size $\mathrm{n} 1$ it is going to be taken values 50,100 and 150. The same sample sizes are going to have the second sample $n_{2}$, too. The acceptance level for the first sample or $c_{7}$ is going to be set at $0,2,4,6,8$ and 10 . Because the acceptance level for the second sample has to be greater than the acceptance level for the first sample, the values of $c_{2}$ are set at values $2,4,8,12,16$ and 20.

In the first step is going to be calculated necessary data for constructing $O C$ curves for each selected sample size. For a double sampling plan it will be construct A and B curves, too. In the second step values of probabilities of lot fraction defectives for selected values of probability of acceptance are taken. In final analysis the probabilities of lot fraction defectives are compared between a single and double sampling plan for each different sample size combination using the test for differences in the two proportions. 


\section{Analysis}

The OC curves of the single and the double sampling plans for different sample sizes at selected levels of maximum allowed number of defective units are shown in Figure 5. It can be noticed that the greater the maximum allowed number of defective units is the further the OC curves are from the $y$-axis. So, for the same value of lot fraction defective, with rising the maximum allowed number of defective units, rises the probability of acceptance, too. But if the maximum allowed number of defective units is kept on the same value and the sample size are rising, the OC curves are closer to the $y$-axis or the smaller values of defective units at the same probabilities of acceptance are allowed. In Figure 5 next to the OC curves tables with calculated lot fraction defectives $\mathrm{p}$ for given the maximum allowed number of defective units or $\mathrm{c}$ and the probabilities of acceptance $P_{a}$ are shown. The data in the tables confirm conclusions which have made with comparing the OC curves.

Figure 5

The OC Curves of a Single Sampling Plan for the Selected Sample Sizes

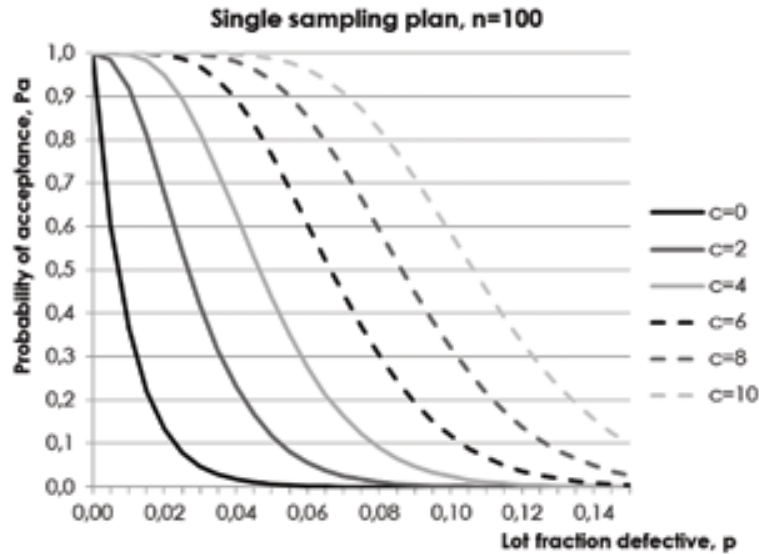

\begin{tabular}{|c|c|c|c|}
\hline \multirow{2}{*}{$c$} & \multicolumn{3}{|c|}{ Lot fraction defectives, $\mathrm{P}$} \\
\cline { 2 - 4 } & $P_{\mathrm{o}}=0.95$ & $P_{\mathrm{e}}=0.50$ & $P_{\mathrm{o}}=0.10$ \\
\hline 0 & 0,000513 & 0,006908 & 0,045007 \\
\hline 2 & 0,000226 & 0,026651 & 0,052345 \\
\hline 4 & 0,019906 & 0,046553 & 0,078348 \\
\hline 6 & 0,033312 & 0,066474 & 0,102939 \\
\hline 8 & 0,047757 & 0,086400 & 0,126698 \\
\hline 10 & 0,062925 & 0,106329 & 0,149883 \\
\hline
\end{tabular}

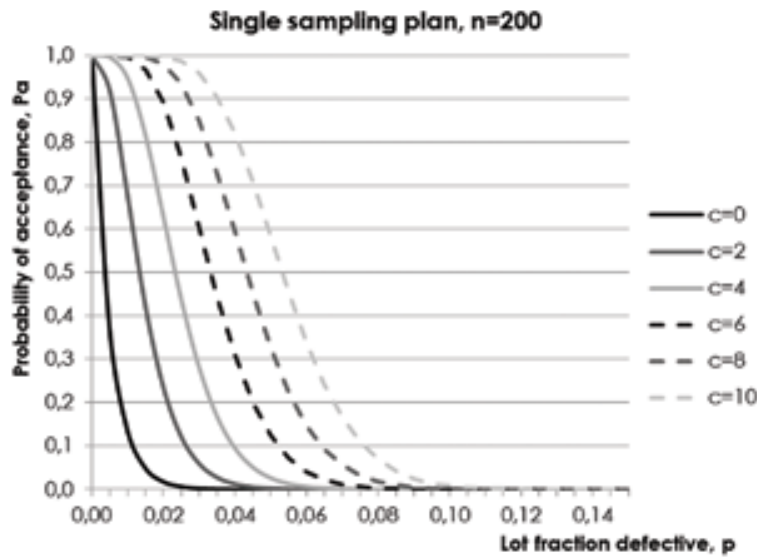

\begin{tabular}{|c|c|c|c|}
\hline \multirow{2}{*}{$c$} & \multicolumn{3}{|c|}{ Lot froction defectives, $\mathrm{P}$} \\
\cline { 2 - 4 } & $\mathrm{P}_{\mathrm{o}}=0.95$ & $\mathrm{P}_{\mathrm{o}}=0.50$ & $\mathrm{P}_{\mathrm{o}}=0,10$ \\
\hline 0 & 0,000256 & 0,003460 & 0,011447 \\
\hline 2 & 0,004101 & 0,013348 & 0,026391 \\
\hline 4 & 0,009901 & 0,023315 & 0,039570 \\
\hline 6 & 0,016540 & 0,033292 & 0,052064 \\
\hline 8 & 0,023674 & 0,043272 & 0,064162 \\
\hline 10 & 0,031147 & 0,053254 & 0,075990 \\
\hline
\end{tabular}

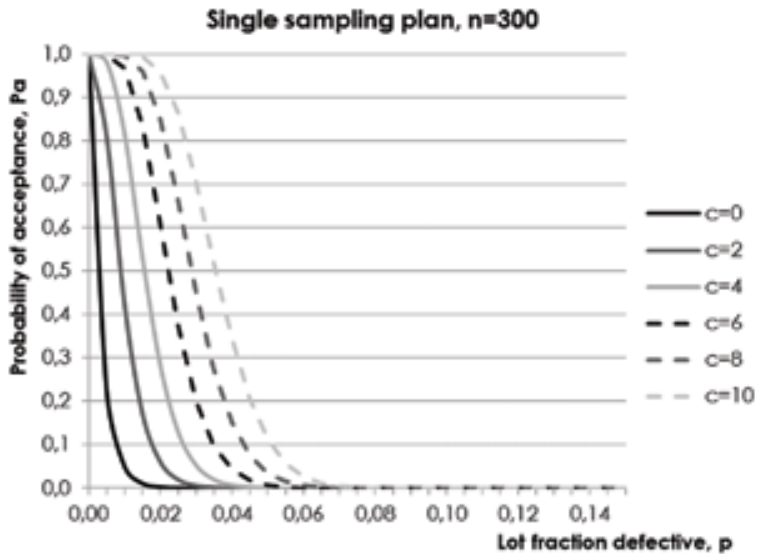

\begin{tabular}{|c|c|c|c|}
\hline \multirow{2}{*}{$\mathrm{c}$} & \multicolumn{3}{|c|}{ Lot froction defectives, $\mathrm{P}$} \\
\cline { 2 - 4 } & $\mathrm{P}_{\mathrm{o}}=0.95$ & $\mathrm{P}_{\mathrm{o}}=0.50$ & $\mathrm{P}_{\mathrm{o}}=0.10$ \\
\hline 0 & 0,000171 & 0,002308 & 0,007646 \\
\hline 2 & 0,002731 & 0,008904 & 0,017643 \\
\hline 4 & 0,006590 & 0,015552 & 0,026468 \\
\hline 6 & 0,011001 & 0,022208 & 0,034842 \\
\hline 8 & 0,015738 & 0,028864 & 0,042955 \\
\hline 10 & 0,020697 & 0,035522 & 0,050892 \\
\hline
\end{tabular}

Source: Author's illustration 
Next to a single sampling plan which has been observed through the three cases of a single sampling plan which differ in a sample size each with six different levels of the maximum allowed number of defective units, a double sampling plan was observed on similar way, too. There are examined five cases of a double sampling plan. In the first case the sample sizes are equal and the samples contain 50 units for inspection. The second case assumes that the second sample is twice bigger than the first. So, in this case sample sizes are $n_{1}=50$ and $n_{2}=100$. In the third case the size of the first sample is doubled and sample sizes are $n_{1}=100$ and $n_{2}=100$. In the forth case sample sizes are $n_{1}=100$ and $n_{2}=150$, and in the fifth case they are $n_{1}=150$ and $n 2=150$. In each case are used the same values of maximum allowed number of defective units. Like in a single sampling plan here are used with six different levels of the maximum allowed number of defective units, too. The values of the maximum allowed number of defective units which are used in a double sampling plan are respectively: $c_{7}=0, c_{2}=2 ; c_{7}=2, c_{2}=4 ; c_{7}=4, c_{2}=8 ; c_{7}=6, c_{2}=12 ; c_{7}=8, c_{2}=16 ; c_{7}=10$, $c_{2}=20$. On basis mentioned values of parameters, elements of curves $A, B$ and $C$ are calculated. But of interest to compare with an OC curve in a single sampling plan here is only curve $C$ which is known as OC curve of a double sampling plan. Curves A and B are known as auxiliary curves and they are calculated on the same way as the OC curve in a single sampling plan so there is no interest of comparing them. In Figure 6 are shown OC curves of a double sampling plan for each observed case and next to them are tables with calculated lot fraction defectives $p$ for given the maximum allowed number of defective units $c_{1}$ and $c_{2}$ and the probabilities of acceptance $P_{a}$.

After the lot fraction defectives had been calculated for simple and double sampling plan at chosen probabilities of acceptance and for chosen values of the maximum allowed number of defective units, tests for differences between two proportions were conducted. The tests which were conducted compared lot fraction defectives between single and double sampling plan for each combination of the maximum allowed number of defective units at the chosen sample sizes. For purposes of testing the first proportion was taken from a single sampling plan, and the second from a double sampling plan. In fact, proportions are the lot fraction defectives taken from both sampling plans at the same levels of probabilities of acceptance. The null hypothesis states that the lot fraction defective is equal in a single and a double sampling plan at the same of probabilities of acceptance. The alternative hypothesis assumes that there is a statistically significant difference between the lot fraction defectives for the same level of probabilities of acceptance between both sampling plans.

In Tables 1, 2 and 3 results of the tests conducted at level of probabilities of acceptance of $0.95,0.50$ and 0.10 are shown. As the value of the a level in the tests is used 0.05. According to that the table limit $z$ value for non-rejecting the null hypothesis is 1.96. In the tables values which are equal or smaller than 1.96 are written in bold. So, the bolded values are showing under which conditions the null hypothesis can not be rejected. In other words, the bolded values are pointing to the situations under which can be concluded that there is no statistically significant difference between simple and double sampling plan in lot fraction defectives for given the maximum allowed number of defective units, and the probabilities of acceptance. 
Figure 6

The OC Curves of a Double Sampling Plan for the Selected Sample Sizes

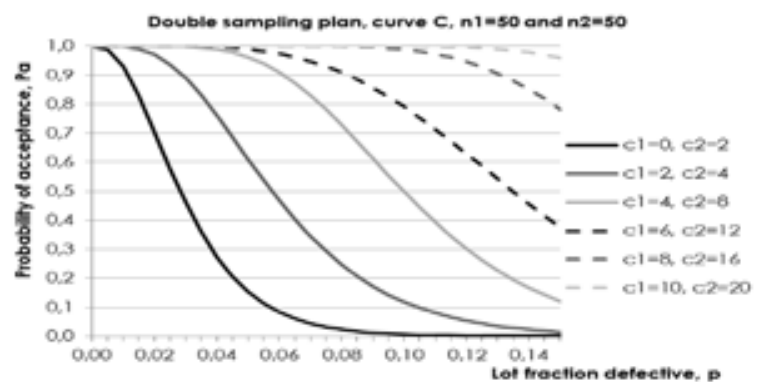

\begin{tabular}{|c|c|c|c|}
\hline \multirow{2}{*}{$\mathrm{c}$} & \multicolumn{3}{|c|}{ Lot traction detoctives, $\mathrm{P}$} \\
\cline { 2 - 4 } & $\mathrm{P}_{\mathrm{o}}=0.95$ & $\mathrm{P}_{\mathrm{o}}=0.50$ & $\mathrm{P}_{\mathrm{o}}=0.10$ \\
\hline 0.2 & 0.006624 & 0.020279 & 0.057026 \\
\hline 2.4 & 0.023494 & 0.057684 & 0.104101 \\
\hline 48 & 0.053083 & 0.079680 & 0.155271 \\
\hline 8.12 & 0.069442 & 0.134027 & 0.201730 \\
\hline 8.16 & 0.118940 & 0.182614 & 0.249306 \\
\hline 10.20 & 0.153720 & 0.223518 & 0.293964 \\
\hline
\end{tabular}

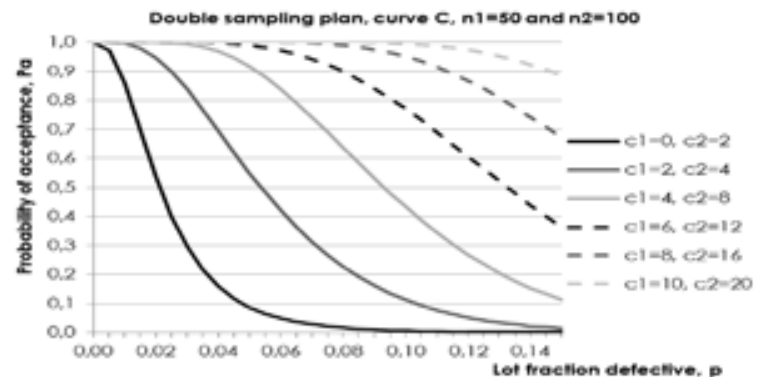

\begin{tabular}{|c|c|c|c|}
\hline \multirow{2}{*}{ c } & \multicolumn{3}{|c|}{ Lot traction detectives, $p$} \\
\hline & $P_{0}=0.95$ & $P_{0}=0.50$ & $P_{0}=0.10$ \\
\hline 0.2 & 0.008241 & 0,021319 & $0.04740^{\circ}$ \\
\hline 244 & 0019749 & 0,053649 & 0,102968 \\
\hline $4: 8$ & 0.044279 & 0.073105 & a.153551 \\
\hline $6: 12$ & 0.067844 & 0.132515 & 0.201131 \\
\hline $8=16$ & 0.100395 & 0,172289 & 0,246875 \\
\hline 1020 & 0.130027 & 0.211975 & 0.29129 \\
\hline
\end{tabular}

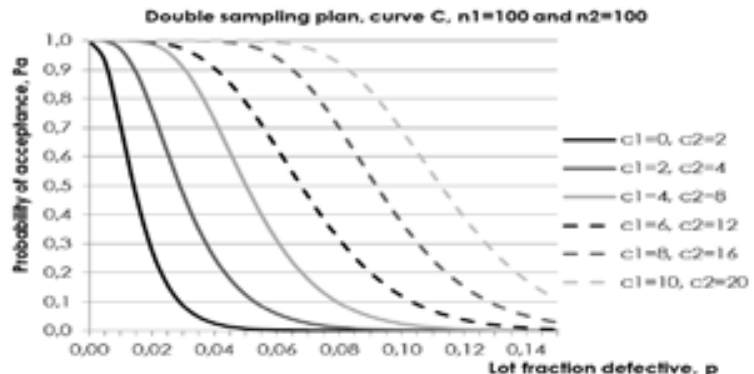

\begin{tabular}{|c|c|c|c|}
\hline \multirow{2}{*}{ a } & \multicolumn{3}{|c|}{ Lot fraction defectives, $p$} \\
\hline & $P_{0}=0.95$ & $P_{0}=0.50$ & $P_{0}=0.10$ \\
\hline 0.2 & 0.004300 & 0,014185 & 0.0280030 \\
\hline 2,4 & 0.011697 & $0,02897 / 4$ & 0,052942 \\
\hline 4.8 & 0.026351 & 0,050206 & 0,079287 \\
\hline $6: 12$ & 0.034328 & 0,067783 & 0,103291 \\
\hline 8,16 & 0.058768 & 0,091900 & 0,128068 \\
\hline 1020 & 0.075796 & 0,112543 & 0,151393 \\
\hline
\end{tabular}

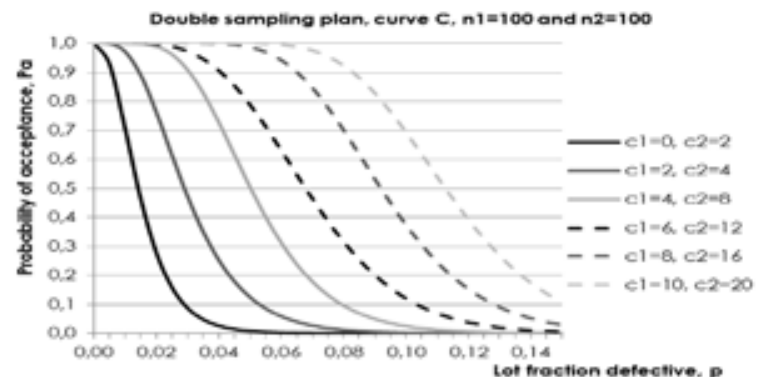

\begin{tabular}{|c|c|c|c|}
\hline \multirow{2}{*}{ e } & \multicolumn{3}{|c|}{ Lot fraction detectives, $P$} \\
\hline & $P_{0}=0.95$ & $P_{q}=0.50$ & $P_{0}=0.10$ \\
\hline$\infty 2$ & 0,004300 & 0.014185 & 0.028638 \\
\hline 24 & 0.011697 & 0.020274 & 0.052742 \\
\hline tot & 0.026351 & 0.050206 & 0.079267 \\
\hline$\$: 12$ & 0,034328 & 0,067783 & 0,103291 \\
\hline 0.16 & $0.05 a 760$ & $0.0 \% 1900$ & 0.126048 \\
\hline 1020 & 0,075796 & 0.112543 & 0.151393 \\
\hline
\end{tabular}

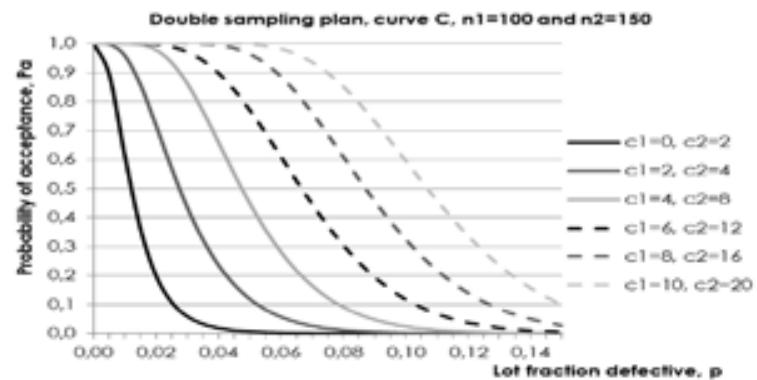

\begin{tabular}{|c|c|c|c|}
\hline \multirow{2}{*}{ e } & \multicolumn{3}{|c|}{ Lot fraction defectives, $p$} \\
\hline & $P_{0}=0.95$ & $P_{9}=0.50$ & $P_{0}=0.10$ \\
\hline 02 & 0.000588 & 0,012044 & 0.025sa: \\
\hline 24 & 0.010537 & 0.027473 & $0.05240:$ \\
\hline $4: 6$ & 0.023523 & 0.047436 & $0.0783 \%$ \\
\hline$\leqslant 12$ & 0.033724 & 0,066591 & 0.102941 \\
\hline 8:16 & 0.052365 & 0.007075 & 0.126718 \\
\hline 1020 & 0.067611 & 0,106878 & Q.14985: \\
\hline
\end{tabular}

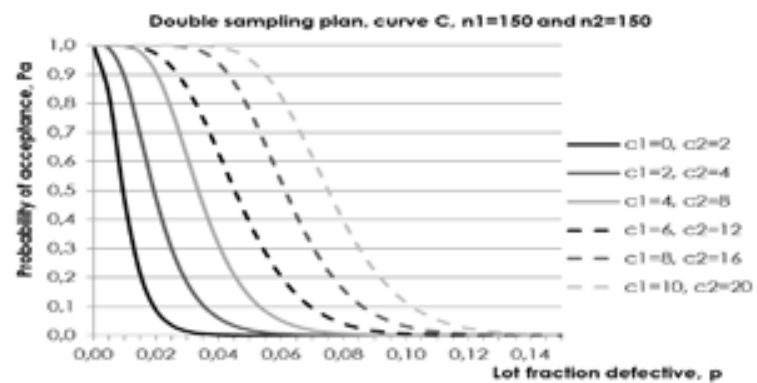

\begin{tabular}{|c|c|c|c|}
\hline \multirow{2}{*}{ c } & \multicolumn{3}{|c|}{ Lot fraction defectives, P } \\
\hline & $P_{0}-0.95$ & $P_{a}=0.50$ & $P_{\alpha}=0,10$ \\
\hline 0.2 & 0.002867 & 0,009467 & 0,019298 \\
\hline 2.4 & 0.007788 & 0,019345 & 0,095495 \\
\hline $4: 8$ & 0.017526 & 0,003530 & 0,053202 \\
\hline $6: 12$ & 0.0228002 & 0,045271 & 0,069101 \\
\hline 8:16 & 0.039030 & 0,051397 & $0,08611)$ \\
\hline 1020 & 0.050308 & 0,075199 & 0,101901 \\
\hline
\end{tabular}

Source: Author's illustration 
Table 1

Absolute Empirical z Test Values for Test for Differences in the Two Proportions, $\mathrm{Pa}=0.95$

\begin{tabular}{|c|c|c|c|c|c|c|c|c|c|c|c|c|c|c|c|c|c|c|}
\hline \multirow{2}{*}{$\begin{array}{l}\text { Double } \\
\text { sampling } \\
\text { plan }\end{array}$} & \multicolumn{6}{|c|}{ Single sampling plan, $n=100$} & \multicolumn{6}{|c|}{ Single sampling plan, $n=200$} & \multicolumn{6}{|c|}{ Single sampling plan, $n=300$} \\
\hline & 0 & 2 & 4 & 6 & 8 & 10 & 0 & 2 & 4 & 6 & 8 & 10 & 0 & 2 & 4 & 6 & 8 & 10 \\
\hline \multicolumn{19}{|c|}{$n_{1}=50 ; n_{2}=50$} \\
\hline $0 ; 2$ & 0,85 & 0,03 & 0,67 & 1,22 & 1,67 & 2,07 & 1,24 & 0,49 & 0,11 & 0,55 & 0,91 & 1,21 & 1,53 & 0,79 & 0,21 & 0,20 & 0,53 & 0,79 \\
\hline $2 ; 4$ & 1,49 & 0,86 & 0,17 & 0,42 & 0,93 & 1,37 & 2,13 & 1,55 & 0,93 & 0,42 & 0,01 & 0,37 & 2,62 & 2,03 & 1,42 & 0,92 & 0,51 & 0,17 \\
\hline $4 ; 8$ & 2,30 & 1,84 & 1,25 & 0,69 & 0,17 & 0,30 & 3,26 & 2,83 & 2,29 & 1,79 & 1,33 & 0,93 & 3,99 & 3,55 & 3,01 & 2,51 & 2,07 & 1,68 \\
\hline $6 ; 12$ & 2,65 & 2,24 & 1,70 & 1,16 & 0,65 & 0,19 & 3,74 & 3,36 & 2,86 & 2,38 & 1,93 & 1,53 & 4,58 & 4,19 & 3,69 & 3,20 & 2,76 & 2,37 \\
\hline $8 ; 16$ & 3,53 & 3,21 & 2,76 & 2,28 & 1,82 & 1,38 & 4,96 & 4,65 & 4,24 & 3,81 & 3,40 & 3,01 & 6,04 & 5,74 & 5,32 & 4,89 & 4,48 & 4,09 \\
\hline $10 ; 20$ & 4,06 & 3,77 & 3,36 & 2,92 & 2,49 & 2,07 & 5,67 & 5,41 & 5,03 & 4,64 & 4,25 & 3,87 & 6,91 & 6,63 & 6,26 & 5,86 & 5,47 & 5,10 \\
\hline
\end{tabular}

\begin{tabular}{|c|c|c|c|c|c|c|c|c|c|c|c|c|c|c|c|c|c|c|}
\hline $0 ; 2$ & $\mathbf{0 , 7 1}$ & $\mathbf{0 , 1 8}$ & $\mathbf{1 , 4 3}$ & $\mathbf{1 , 6 2}$ & $\mathbf{2 , 1 5}$ & 2,62 & $\mathbf{1 , 0 4}$ & $\mathbf{0 , 2 8}$ & $\mathbf{0 , 3 7}$ & $\mathbf{0 , 8 7}$ & $\mathbf{1 , 2 8}$ & $\mathbf{1 , 6 3}$ & $\mathbf{1 , 3 0}$ & $\mathbf{0 , 5 6}$ & $\mathbf{0 , 0 4}$ & $\mathbf{0 , 4 9}$ & $\mathbf{0 , 8 5}$ & $\mathbf{1 , 1 6}$ \\
\hline $2 ; 4$ & $\mathbf{1 , 3 7}$ & $\mathbf{0 , 7 3}$ & $\mathbf{1 , 1 1}$ & $\mathbf{0 , 6 7}$ & $\mathbf{1 , 2 5}$ & $\mathbf{1 , 7 7}$ & $\mathbf{1 , 9 5}$ & $\mathbf{1 , 4 0}$ & $\mathbf{0 , 7 7}$ & $\mathbf{0 , 2 2}$ & $\mathbf{0 , 2 5}$ & $\mathbf{0 , 6 6}$ & 2,40 & $\mathbf{1 , 8 6}$ & $\mathbf{1 , 2 6}$ & $\mathbf{0 , 7 5}$ & $\mathbf{0 , 3 1}$ & $\mathbf{0 , 0 7}$ \\
\hline $4 ; 8$ & 2,10 & $\mathbf{1 , 6 4}$ & $\mathbf{0 , 8 4}$ & $\mathbf{0 , 4 3}$ & $\mathbf{0 , 1 3}$ & $\mathbf{0 , 6 5}$ & 2,98 & 2,58 & 2,05 & $\mathbf{1 , 5 5}$ & $\mathbf{1 , 0 8}$ & $\mathbf{0 , 6 5}$ & 3,64 & 3,25 & 2,75 & 2,26 & $\mathbf{1 , 8 2}$ & $\mathbf{1 , 4 2}$ \\
\hline $6 ; 12$ & 2,63 & 2,25 & $\mathbf{0 , 7 2}$ & $\mathbf{1 , 1 8}$ & $\mathbf{0 , 6 6}$ & $\mathbf{0 , 1 5}$ & 3,72 & 3,38 & 2,93 & 2,47 & 2,02 & $\mathbf{1 , 6 1}$ & 4,54 & 4,22 & 3,78 & 3,33 & 2,91 & 2,52 \\
\hline $8 ; 16$ & 3,25 & 2,93 & $\mathbf{0 , 6 1}$ & 1,99 & $\mathbf{1 , 5 1}$ & $\mathbf{1 , 0 4}$ & 4,56 & 4,28 & 3,89 & 3,48 & 3,08 & 2,68 & 5,56 & 5,29 & 4,92 & 4,52 & 4,13 & 3,76 \\
\hline $10 ; 20$ & 3,75 & 3,47 & $\mathbf{0 , 5 5}$ & 2,62 & 2,17 & $\mathbf{1 , 7 3}$ & 5,25 & 5,00 & 4,65 & 4,28 & 3,90 & 3,53 & 6,39 & 6,15 & 5,81 & 5,45 & 5,09 & 4,74 \\
\hline \multicolumn{10}{|c|}{$n_{1}=100 ; n_{2}=100$} &
\end{tabular}

\begin{tabular}{|c|c|c|c|c|c|c|c|c|c|c|c|c|c|c|c|c|c|c|}
\hline $0 ; 2$ & 0,56 & 0,43 & 1,31 & 2,02 & 2,61 & 3,14 & 0,85 & 0,03 & 0,67 & 1,20 & 1,65 & 2,03 & 1,06 & 0,30 & 0,33 & 0,81 & 1,19 & 1,52 \\
\hline $2 ; 4$ & 1,03 & 0,28 & 0,56 & 1,30 & 1,93 & 2,50 & 1,48 & 0,86 & 0,17 & 0,41 & 0,91 & 1,34 & 1,83 & 1,24 & 0,60 & 0,07 & 0,38 & 0,76 \\
\hline $4 ; 8$ & 1,60 & 1,05 & 0,34 & 0,34 & 0,97 & 1,55 & 2,28 & 1,82 & 1,23 & 0,68 & 0,17 & 0,29 & 2,79 & 2,36 & 1,81 & 1,30 & 0,83 & 0,41 \\
\hline $6 ; 12$ & 1,84 & 1,35 & 0,70 & 0,05 & 0,57 & 1,14 & 2,61 & 2,20 & 1,66 & 1,13 & 0,63 & 0,18 & 3,20 & 2,81 & 2,31 & 1,81 & 1,35 & 0,94 \\
\hline $8 ; 16$ & 2,45 & 2,06 & 1,52 & 0,95 & 0,39 & 0,14 & 3,46 & 3,13 & 2,68 & 2,22 & 1,77 & 1,33 & 4,23 & 3,92 & 3,50 & 3,06 & 2,64 & 2,24 \\
\hline $10 ; 20$ & 2,80 & 2,46 & 1,97 & 1,44 & 0,92 & 0,41 & 3,95 & 3,66 & 3,25 & 2,82 & 2,40 & 1,98 & 4,82 & 4,55 & 4,17 & 3,76 & 3,37 & 2,98 \\
\hline
\end{tabular}

\begin{tabular}{|c|c|c|c|c|c|c|c|c|c|c|c|c|c|c|c|c|c|c|}
\hline $0 ; 2$ & $\mathbf{0 , 5 0}$ & $\mathbf{0 , 5 6}$ & $\mathbf{1 , 5 2}$ & 2,30 & 2,96 & 3,54 & $\mathbf{0 , 7 7}$ & $\mathbf{0 , 0 9}$ & $\mathbf{0 , 8 3}$ & $\mathbf{1 , 4 2}$ & $\mathbf{1 , 9 0}$ & 2,33 & $\mathbf{0 , 9 6}$ & $\mathbf{0 , 1 8}$ & $\mathbf{0 , 4 9}$ & $\mathbf{0 , 9 9}$ & $\mathbf{1 , 4 1}$ & $\mathbf{1 , 7 7}$ \\
\hline $2 ; 4$ & $\mathbf{0 , 9 7}$ & $\mathbf{0 , 2 0}$ & $\mathbf{0 , 6 9}$ & $\mathbf{1 , 4 9}$ & 2,19 & 2,81 & $\mathbf{1 , 4 1}$ & $\mathbf{0 , 7 8}$ & $\mathbf{0 , 0 7}$ & $\mathbf{0 , 5 5}$ & $\mathbf{1 , 0 9}$ & $\mathbf{1 , 5 6}$ & $\mathbf{1 , 7 4}$ & $\mathbf{1 , 1 5}$ & $\mathbf{0 , 5 1}$ & $\mathbf{0 , 0 5}$ & $\mathbf{0 , 5 3}$ & $\mathbf{0 , 9 4}$ \\
\hline $4 ; 8$ & $\mathbf{1 , 5 1}$ & $\mathbf{0 , 9 4}$ & $\mathbf{0 , 2 1}$ & $\mathbf{0 , 5 2}$ & $\mathbf{1 , 1 9}$ & $\mathbf{1 , 8 2}$ & 2,15 & $\mathbf{1 , 6 9}$ & $\mathbf{1 , 1 0}$ & $\mathbf{0 , 5 2}$ & $\mathbf{0 , 0 1}$ & $\mathbf{0 , 5 0}$ & 2,64 & 2,21 & $\mathbf{1 , 6 7}$ & $\mathbf{1 , 1 4}$ & $\mathbf{0 , 6 6}$ & $\mathbf{0 , 2 3}$ \\
\hline $6 ; 12$ & $\mathbf{1 , 8 3}$ & $\mathbf{1 , 3 4}$ & $\mathbf{0 , 6 9}$ & $\mathbf{0 , 0 2}$ & $\mathbf{0 , 6 2}$ & $\mathbf{1 , 2 3}$ & 2,59 & 2,20 & $\mathbf{1 , 6 7}$ & $\mathbf{1 , 1 4}$ & $\mathbf{0 , 6 3}$ & $\mathbf{0 , 1 5}$ & 3,18 & 2,81 & 2,33 & $\mathbf{1 , 8 4}$ & $\mathbf{1 , 3 7}$ & $\mathbf{0 , 9 5}$ \\
\hline $8 ; 16$ & 2,31 & $\mathbf{1 , 9 1}$ & $\mathbf{1 , 3 5}$ & $\mathbf{0 , 7 6}$ & $\mathbf{0 , 1 8}$ & $\mathbf{0 , 3 9}$ & 3,26 & 2,94 & 2,49 & 2,02 & $\mathbf{1 , 5 5}$ & $\mathbf{1 , 1 0}$ & 3,99 & 3,69 & 3,27 & 2,84 & 2,42 & 2,01 \\
\hline $10 ; 20$ & 2,64 & 2,29 & $\mathbf{1 , 7 8}$ & $\mathbf{1 , 2 4}$ & $\mathbf{0 , 7 0}$ & $\mathbf{0 , 1 6}$ & 3,73 & 3,44 & 3,03 & 2,60 & 2,16 & $\mathbf{1 , 7 4}$ & 4,56 & 4,29 & 3,91 & 3,51 & 3,12 & 2,73 \\
\hline \multicolumn{10}{|c|}{$n_{1}=150 ; n_{2}=150$} \\
\hline
\end{tabular}

\begin{tabular}{|c|c|c|c|c|c|c|c|c|c|c|c|c|c|c|c|c|c|c|}
\hline $0 ; 2$ & ,43 & 0,72 & 1,75 & 2,59 & 3,30 & 3,92 & 0,67 & 0,23 & 1,03 & 1,65 & 2,17 & 2,62 & 0,85 & 0,03 & 0,66 & 1,20 & 1,64 & 2,04 \\
\hline $2 ; 4$ & 82 & 0,04 & 1,01 & 1,87 & 2,62 & 3,29 & 1,20 & 0,51 & 0,25 & 0,91 & 1,47 & 1,97 & 1,48 & 0,86 & 0,17 & 0,41 & 0,90 & 1,37 \\
\hline $4 ; 8$ & 1,29 & 0 , & 0,15 & 0,94 & 1,6 & 2,35 & 1,85 & 1,34 & 0,7 & 0,08 & 0,4 & 1,0 & 2,21 & 1,81 & 23 & 77 & 0,17 & 0,29 \\
\hline 6 & 148 & 0 & 0 , & 0,58 & 1,2 & 195 & 2, & 1, & 1,0 & 0 , & 0, & 0,5 & 2, & 2,19 & 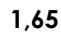 & 1, & 63 & 0,18 \\
\hline $8 ; 16$ & 1,97 & 1,53 & 0,91 & 0,26 & 0,38 & 1,00 & 2,8 & 2,45 & 1,96 & 1,44 & 0,94 & 0,46 & 3 & 3, & 6 & 2,20 & 1,75 & 1,40 \\
\hline $10 ; 20$ & 2,26 & 1,86 & 1,30 & 0,70 & 0,10 & 0,49 & 3,20 & 2,88 & 2,44 & 1,96 & 1,50 & 1,04 & 3,91 & 3,63 & 3,22 & 2,79 & 2,37 & 2,08 \\
\hline
\end{tabular}

Note: Numbers in bold formatting indicate that there is no statistically significant difference between simple and double sampling plan in lot fraction defectives for given the maximum allowed number of defective units, and the probabilities of acceptance.

Source: Author's calculation 
Table 2

Absolute Empirical z Test Values for Test for Differences in the Two Proportions, $\mathrm{Pa}=0.50$

\begin{tabular}{|c|c|c|c|c|c|c|c|c|c|c|c|c|c|c|c|c|c|c|}
\hline \multirow{2}{*}{$\begin{array}{c}\text { Double } \\
\text { sampling } \\
\text { plan }\end{array}$} & \multicolumn{6}{|c|}{ Single sampling plan, $n=100$} & \multicolumn{6}{|c|}{ Single sampling plan, $n=200$} & \multicolumn{6}{|c|}{ Single sampling plan, $n=300$} \\
\hline & 0 & 2 & 4 & 6 & 8 & 10 & 0 & 2 & 4 & 6 & 8 & 10 & 0 & 2 & 4 & 6 & 8 & 10 \\
\hline \multicolumn{19}{|c|}{$n_{1}=50 ; n_{2}=50$} \\
\hline $0 ; 2$ & 1,15 & 0,07 & 0,68 & 1,27 & 1,77 & 2,20 & 1,88 & 0,91 & 0,26 & 0,23 & 0,64 & 0,98 & 2,41 & 1,44 & 0,81 & 0,35 & 0,03 & 0,35 \\
\hline $2 ; 4$ & 2,03 & 1,09 & 0,35 & 0,26 & 0,79 & 1,25 & 3,05 & 2,19 & 1,53 & 1,00 & 0,55 & 0,16 & 3,80 & 2,94 & 2,29 & 1,77 & 1,34 & 0,97 \\
\hline $4 ; 8$ & 2,92 & 2,13 & 1,45 & 0,86 & 0,33 & 0,15 & 4,25 & 3,51 & 2,90 & 2,37 & 1,91 & 1,50 & 5,24 & 4,50 & 3,89 & 3,37 & 2,92 & 2,52 \\
\hline $6 ; 12$ & 3,52 & 2,81 & 2,17 & 1,61 & 1,09 & 0,62 & 5,06 & 4,39 & 3,82 & 3,31 & 2,86 & 2,45 & 6,21 & 5,54 & 4,96 & 4,46 & 4,01 & 3,61 \\
\hline $8 ; 16$ & 4,24 & 3,60 & 3,02 & 2,49 & 1,99 & 1,53 & 6,01 & 5,42 & 4,90 & 4,42 & 3,98 & 3,58 & 7,35 & 6,76 & 6,22 & 5,75 & 5,31 & 4,92 \\
\hline $10 ; 20$ & 4,80 & 4,21 & 3,66 & 3,15 & 2,68 & 2,23 & 6,75 & 6,21 & 5,71 & 5,26 & 4,83 & 4,44 & 8,22 & 7,67 & 7,18 & 6,72 & 6,30 & 5,92 \\
\hline \multicolumn{19}{|c|}{$n_{1}=50 ; n_{2}=100$} \\
\hline $0 ; 2$ & 0,90 & 0,27 & 2,07 & 1,80 & 2,37 & 2,88 & 1,58 & 0,57 & 0,12 & 0,67 & 1,12 & 1,52 & 2,05 & 1,09 & 0,44 & 0,06 & 0,47 & 0,82 \\
\hline $2 ; 4$ & 1,97 & 1,03 & 1,64 & 0,42 & 1,02 & 1,55 & 2,98 & 2,17 & 1,50 & 0,94 & 0,45 & 0,02 & 3,72 & 2,93 & 2,30 & 1,77 & 1,31 & 0,91 \\
\hline $4 ; 8$ & 2,84 & 2,07 & 1,37 & 0,75 & 0,18 & 0,34 & 4,14 & 3,47 & 2,88 & 2,35 & 1,88 & 1,44 & 5,11 & 4,46 & 3,89 & 3,39 & 2,94 & 2,53 \\
\hline $6 ; 12$ & 3,54 & 2,86 & 1,21 & 1,66 & 1,12 & 0,62 & 5,08 & 4,49 & 3,96 & 3,47 & 3,02 & 2,60 & 6,23 & 5,67 & 5,15 & 4,68 & 4,25 & 3,86 \\
\hline $8 ; 16$ & 4,16 & 3,55 & 1,10 & 2,44 & 1,93 & 1,45 & 5,90 & 5,38 & 4,89 & 4,43 & 4,01 & 3,61 & 7,22 & 6,71 & 6,23 & 5,80 & 5,39 & 5,01 \\
\hline $10 ; 20$ & 4,72 & 4,16 & 1,02 & 3,12 & 2,64 & 2,18 & 6,65 & 6,17 & 5,72 & 5,29 & 4,89 & 4,50 & 8,10 & 7,64 & 7,20 & 6,79 & 6,40 & 6,04 \\
\hline \multicolumn{19}{|c|}{$n_{1}=100 ; n_{2}=100$} \\
\hline $0 ; 2$ & 0,55 & 0,76 & 1,69 & 2,44 & 3,07 & 3,63 & 1,15 & 0,07 & 0,67 & 1,26 & 1,74 & 2,16 & 1,55 & 0,55 & 0,12 & 0,64 & 1,07 & 1,44 \\
\hline $2 ; 4$ & 1,24 & 0,11 & 0,78 & 1,54 & 2,19 & 2,78 & 2,02 & 1,09 & 0,35 & 0,25 & 0,77 & 1,22 & 2,58 & 1,70 & 1,03 & 0,48 & 0,01 & 0,40 \\
\hline $4 ; 8$ & 1,90 & 0,95 & 0,14 & 0,58 & 1,22 & 1,81 & 2,89 & 2,10 & 1,43 & 0,85 & 0,33 & 0,14 & 3,62 & 2,87 & 2,25 & 1,71 & 1,23 & 0,81 \\
\hline $6 ; 12$ & 2,34 & 1,48 & 0,73 & 0,04 & 0,58 & 1,16 & 3,47 & 2,76 & 2,13 & 1,57 & 1,07 & 0,61 & 4,31 & 3,64 & 3,05 & 2,53 & 2,07 & 1,65 \\
\hline $8 ; 16$ & 2,84 & 2,09 & 1,39 & 0,75 & 0,16 & 0,40 & 4,15 & 3,52 & 2,94 & 2,42 & 1,94 & 1,49 & 5,12 & 4,53 & 3,99 & 3,50 & 3,05 & 2,64 \\
\hline $10 ; 20$ & 3,23 & 2,53 & 1,88 & 1,27 & 0,70 & 0,16 & 4,67 & 4,08 & 3,55 & 3,05 & 2,58 & 2,15 & 5,74 & 5,19 & 4,69 & 4,22 & 3,79 & 3,39 \\
\hline \multicolumn{19}{|c|}{$n_{1}=100 ; n_{2}=150$} \\
\hline $0 ; 2$ & 0,42 & 0,98 & 1,99 & 2,81 & 3,50 & 4,12 & 1,00 & 0,12 & 0,92 & 1,54 & 2,07 & 2,53 & 1,39 & 0,36 & 0,35 & 0,90 & 1,36 & 1,76 \\
\hline $2 ; 4$ & 1,20 & 0,04 & 0,90 & 1,71 & 2,42 & 3,06 & 1,97 & 1,03 & 0,28 & 0,36 & 0,91 & 1,40 & 2,52 & 1,66 & 0,97 & 0,40 & 0,10 & 0,54 \\
\hline $4 ; 8$ & 1,84 & 0,88 & 0,04 & 0,72 & 1,40 & 2,03 & 2,82 & 2,03 & 1,35 & 0,75 & 0,21 & 0,28 & 3,53 & 2,81 & 2,18 & 1,63 & 1,14 & 0,70 \\
\hline $6 ; 12$ & 2,32 & 1,48 & 0,71 & 0,00 & 0,65 & 1,25 & 3,46 & 2,77 & 2,15 & 1,58 & 1,07 & 0,59 & 4,30 & 3,66 & 3,09 & 2,57 & 2,10 & 1,67 \\
\hline $8 ; 16$ & 2,76 & 2,00 & 1,30 & 0,64 & 0,02 & 0,56 & 4,05 & 3,43 & 2,86 & 2,33 & 1,84 & 1,38 & 5,00 & 4,43 & 3,90 & 3,42 & 2,97 & 2,56 \\
\hline $10 ; 20$ & 3,14 & 2,44 & 1,78 & 1,16 & 0,57 & 0,02 & 4,56 & 3,99 & 3,46 & 2,96 & 2,49 & 2,05 & 5,61 & 5,09 & 4,60 & 4,14 & 3,71 & 3,31 \\
\hline \multicolumn{19}{|c|}{$n_{1}=150 ; n_{2}=150$} \\
\hline $0 ; 2$ & 0,24 & 1,28 & 2,37 & 3,24 & 3,99 & 4,65 & 0,79 & 0,41 & 1,25 & 1,91 & 2,47 & 2,96 & 1,15 & 0,07 & 0,67 & 1,25 & 1,73 & 2,19 \\
\hline $2 ; 4$ & 0,85 & 0,44 & 1,48 & 2,35 & 3,11 & 3,79 & 1,54 & 0,51 & 0,30 & 0,98 & 1,56 & 2,08 & 2,02 & 1,08 & 0,35 & 0,25 & 0,76 & 1,25 \\
\hline $4 ; 8$ & 1,43 & 0,34 & 0,60 & 1,43 & 2,17 & 2,85 & 2,27 & 1,40 & 0,66 & 0,01 & 0,56 & 1,08 & 2,88 & 2,09 & 1,42 & 0,84 & 0,33 & 0,14 \\
\hline $6 ; 12$ & 1,79 & 0,82 & 0,05 & 0,84 & 1,56 & 2,22 & 2,75 & 1,97 & 1,28 & 0,67 & 0,11 & 0,41 & 3,45 & 2,74 & 2,12 & 1,56 & 1,06 & 0,64 \\
\hline $8 ; 16$ & 2,21 & 1,35 & 0,55 & 0,18 & 0,86 & 1,50 & 3,31 & 2,62 & 1,99 & 1,41 & 0,88 & 0,38 & 4,12 & 3,49 & 2,92 & 2,40 & 1,92 & 1,56 \\
\hline $10 ; 20$ & 2,53 & 1,73 & 0,99 & 0,29 & 0,36 & 0,98 & 3,73 & 3,10 & 2,50 & 1,96 & 1,45 & 0,97 & 4,63 & 4,05 & 3,51 & 3,02 & 2,56 & 2,25 \\
\hline
\end{tabular}

Note: Numbers in bold formatting indicate that there is no statistically significant difference between simple and double sampling plan in lot fraction defectives for given the maximum allowed number of defective units, and the probabilities of acceptance.

Source: Author's calculation 
Table 3

Absolute Empirical z Test Values for Test for Differences in the Two Proportions, $\mathrm{Pa}=0.10$

\begin{tabular}{|c|c|c|c|c|c|c|c|c|c|c|c|c|c|c|c|c|c|c|}
\hline \multirow{2}{*}{$\begin{array}{l}\text { Double } \\
\text { sampling } \\
\text { plan }\end{array}$} & \multicolumn{6}{|c|}{ Single sampling plan, $n=100$} & \multicolumn{6}{|c|}{ Single sampling plan, $n=200$} & \multicolumn{6}{|c|}{ Single sampling plan, $n=300$} \\
\hline & 0 & 2 & 4 & 6 & 8 & 10 & 0 & 2 & 4 & 6 & 8 & 10 & 0 & 2 & 4 & 6 & 8 & 10 \\
\hline
\end{tabular}

\begin{tabular}{|c|l|l|l|l|l|l|l|l|l|l|l|l|l|l|l|l|l|l|}
\hline $0 ; 2$ & $\mathbf{0 , 3 9}$ & $\mathbf{0 , 1 5}$ & $\mathbf{0 , 6 0}$ & $\mathbf{1 , 2 0}$ & $\mathbf{1 , 7 1}$ & 2,16 & 2,31 & $\mathbf{1 , 3 3}$ & $\mathbf{0 , 6 8}$ & $\mathbf{0 , 1 8}$ & $\mathbf{0 , 2 4}$ & $\mathbf{0 , 6 1}$ & 3,06 & 2,09 & $\mathbf{1 , 4 6}$ & $\mathbf{0 , 9 8}$ & $\mathbf{0 , 5 8}$ & $\mathbf{0 , 2 4}$ \\
\hline $2 ; 4$ & $\mathbf{1 , 5 9}$ & $\mathbf{1 , 3 6}$ & $\mathbf{0 , 6 3}$ & $\mathbf{0 , 0 3}$ & $\mathbf{0 , 5 0}$ & $\mathbf{0 , 9 7}$ & 3,76 & 2,85 & 2,20 & $\mathbf{1 , 6 7}$ & $\mathbf{1 , 2 2}$ & $\mathbf{0 , 8 2}$ & 4,76 & 3,86 & 3,21 & 2,70 & 2,26 & $\mathbf{1 , 8 8}$ \\
\hline $4 ; 8$ & 2,60 & 2,39 & $\mathbf{1 , 6 9}$ & $\mathbf{1 , 1 0}$ & $\mathbf{0 , 5 8}$ & $\mathbf{0 , 1 1}$ & 4,97 & 4,14 & 3,52 & 3,00 & 2,54 & 2,14 & 6,20 & 5,37 & 4,75 & 4,23 & 3,79 & 3,39 \\
\hline $6 ; 12$ & 3,37 & 3,17 & 2,51 & $\mathbf{1 , 9 4}$ & $\mathbf{1 , 4 3}$ & $\mathbf{0 , 9 6}$ & 5,90 & 5,14 & 4,55 & 4,04 & 3,59 & 3,18 & 7,30 & 6,53 & 5,94 & 5,44 & 4,99 & 4,60 \\
\hline $8 ; 16$ & 4,08 & 3,89 & 3,27 & 2,72 & 2,22 & $\mathbf{1 , 7 6}$ & 6,76 & 6,05 & 5,48 & 5,00 & 4,56 & 4,16 & 8,31 & 7,59 & 7,03 & 6,54 & 6,11 & 5,72 \\
\hline $10 ; 20$ & 4,69 & 4,52 & 3,92 & 3,39 & 2,90 & 2,45 & 7,51 & 6,83 & 6,29 & 5,82 & 5,40 & 5,00 & 9,18 & 8,50 & 7,96 & 7,49 & 7,07 & 6,68 \\
\hline \multicolumn{19}{|c|}{$n_{1}=50 ; n_{2}=100$} \\
\hline
\end{tabular}

\begin{tabular}{|c|l|l|l|l|l|l|l|l|l|l|l|l|l|l|l|l|l|l|}
\hline $0 ; 2$ & $\mathbf{0 , 0 9}$ & $\mathbf{0 , 1 7}$ & 2,56 & $\mathbf{1 , 6 9}$ & 2,27 & 2,79 & 2,06 & $\mathbf{1 , 0 6}$ & $\mathbf{0 , 3 6}$ & $\mathbf{0 , 1 9}$ & $\mathbf{0 , 6 7}$ & $\mathbf{1 , 0 8}$ & 2,78 & $\mathbf{1 , 8 2}$ & $\mathbf{1 , 1 7}$ & $\mathbf{0 , 6 5}$ & $\mathbf{0 , 2 2}$ & $\mathbf{0 , 1 6}$ \\
\hline $2 ; 4$ & $\mathbf{1 , 6 6}$ & $\mathbf{1 , 4 2}$ & 2,09 & $\mathbf{0 , 0 0}$ & $\mathbf{0 , 5 8}$ & $\mathbf{1 , 1 1}$ & 3,86 & 3,00 & 2,35 & $\mathbf{1 , 8 0}$ & $\mathbf{1 , 3 2}$ & $\mathbf{0 , 8 8}$ & 4,90 & 4,07 & 3,45 & 2,93 & 2,47 & 2,07 \\
\hline $4 ; 8$ & 2,69 & 2,48 & $\mathbf{1 , 8 4}$ & $\mathbf{1 , 1 5}$ & $\mathbf{0 , 5 9}$ & $\mathbf{0 , 0 8}$ & 5,08 & 4,32 & 3,72 & 3,20 & 2,73 & 2,30 & 6,33 & 5,60 & 5,02 & 4,52 & 4,08 & 3,68 \\
\hline $6 ; 12$ & 3,50 & 3,31 & $\mathbf{1 , 6 9}$ & 2,07 & $\mathbf{1 , 5 3}$ & $\mathbf{1 , 0 3}$ & 6,05 & 5,36 & 4,80 & 4,31 & 3,86 & 3,45 & 7,48 & 6,81 & 6,27 & 5,80 & 5,38 & 4,99 \\
\hline $8 ; 16$ & 4,20 & 4,02 & $\mathbf{1 , 5 8}$ & 2,85 & 2,33 & $\mathbf{1 , 8 5}$ & 6,90 & 6,26 & 5,74 & 5,27 & 4,84 & 4,44 & 8,47 & 7,85 & 7,35 & 6,90 & 6,49 & 6,12 \\
\hline $10 ; 20$ & 4,84 & 4,67 & $\mathbf{1 , 5 0}$ & 3,55 & 3,05 & 2,58 & 7,67 & 7,07 & 6,57 & 6,13 & 5,71 & 5,33 & 9,36 & 8,79 & 8,31 & 7,88 & 7,49 & 7,12 \\
\hline \multicolumn{10}{|c|}{$n_{1}=100 ; n_{2}=100$} &
\end{tabular}

\begin{tabular}{|c|l|l|l|l|l|l|l|l|l|l|l|l|l|l|l|l|l|l|}
\hline $0 ; 2$ & $\mathbf{0 , 7 3}$ & $\mathbf{1 , 0 2}$ & $\mathbf{1 , 9 4}$ & 2,69 & 3,33 & 3,89 & $\mathbf{1 , 2 4}$ & $\mathbf{0 , 1 5}$ & $\mathbf{0 , 5 9}$ & $\mathbf{1 , 1 8}$ & $\mathbf{1 , 6 8}$ & 2,12 & $\mathbf{1 , 8 4}$ & $\mathbf{0 , 8 3}$ & $\mathbf{0 , 1 6}$ & $\mathbf{0 , 3 7}$ & $\mathbf{0 , 8 2}$ & $\mathbf{1 , 2 0}$ \\
\hline $2 ; 4$ & $\mathbf{0 , 3 0}$ & $\mathbf{0 , 0 2}$ & $\mathbf{0 , 8 6}$ & $\mathbf{1 , 6 0}$ & 2,25 & 2,83 & 2,35 & $\mathbf{1 , 3 6}$ & $\mathbf{0 , 6 4}$ & $\mathbf{0 , 0 4}$ & $\mathbf{0 , 4 8}$ & $\mathbf{0 , 9 4}$ & 3,13 & 2,20 & $\mathbf{1 , 5 4}$ & $\mathbf{0 , 9 9}$ & $\mathbf{0 , 5 2}$ & $\mathbf{0 , 1 0}$ \\
\hline $4 ; 8$ & $\mathbf{1 , 1 1}$ & $\mathbf{0 , 8 6}$ & $\mathbf{0 , 0 3}$ & $\mathbf{0 , 6 9}$ & $\mathbf{1 , 3 2}$ & $\mathbf{1 , 9 0}$ & 3,26 & 2,36 & $\mathbf{1 , 6 8}$ & $\mathbf{1 , 1 0}$ & $\mathbf{0 , 5 9}$ & $\mathbf{0 , 1 2}$ & 4,20 & 3,35 & 2,72 & 2,18 & $\mathbf{1 , 7 1}$ & $\mathbf{1 , 2 9}$ \\
\hline $6 ; 12$ & $\mathbf{1 , 7 2}$ & $\mathbf{1 , 4 8}$ & $\mathbf{0 , 6 9}$ & $\mathbf{0 , 0 1}$ & $\mathbf{0 , 6 1}$ & $\mathbf{1 , 1 8}$ & 3,95 & 3,12 & 2,47 & $\mathbf{1 , 9 1}$ & $\mathbf{1 , 4 1}$ & $\mathbf{0 , 9 6}$ & 5,01 & 4,23 & 3,62 & 3,10 & 2,64 & 2,22 \\
\hline $8 ; 16$ & 2,26 & 2,04 & $\mathbf{1 , 2 9}$ & $\mathbf{0 , 6 3}$ & $\mathbf{0 , 0 3}$ & $\mathbf{0 , 5 2}$ & 4,58 & 3,81 & 3,19 & 2,65 & 2,17 & $\mathbf{1 , 7 2}$ & 5,75 & 5,02 & 4,45 & 3,95 & 3,50 & 3,08 \\
\hline $10 ; 20$ & 2,71 & 2,50 & $\mathbf{1 , 7 9}$ & $\mathbf{1 , 1 6}$ & $\mathbf{0 , 5 8}$ & $\mathbf{0 , 0 3}$ & 5,12 & 4,39 & 3,81 & 3,29 & 2,81 & 2,38 & 6,38 & 5,70 & 5,15 & 4,67 & 4,23 & 3,83 \\
\hline \multicolumn{10}{|c|}{$n_{1}=100 ; n_{2}=150$} &
\end{tabular}

\begin{tabular}{|c|c|c|c|c|c|c|c|c|c|c|c|c|c|c|c|c|c|c|}
\hline $0 ; 2$ & 0,94 & 1,26 & 2,26 & 3,07 & 3,77 & 4,39 & 1,08 & 0,05 & 0,84 & 1,47 & 2,01 & 2,49 & 1,68 & 0,64 & 0,06 & 0,63 & 1,10 & 1,52 \\
\hline $2 ; 4$ & 0,29 & 0,00 & 0,92 & 1,71 & 2,40 & 3,03 & 2,38 & 1,39 & 0,64 & 0,02 & 0,53 & 1,02 & 3,17 & 2,26 & 1,58 & 1,01 & 0,52 & 0,08 \\
\hline $4 ; 8$ & 1,11 & 0,86 & 0,00 & 0,74 & 1,41 & 2,02 & 3,28 & 2,40 & 1,71 & 1,11 & 0,58 & 0,09 & 4,23 & 3,41 & 2,78 & 2,24 & 1,76 & 1,32 \\
\hline $6 ; 12$ & 1,74 & 1,51 & 0,71 & 0,00 & 0,64 & 1,24 & 3,99 & 3,19 & 2,54 & 1,97 & 1,46 & 0,99 & 5,06 & 4,32 & 3,72 & 3,21 & 2,74 & 2,31 \\
\hline $8 ; 16$ & 2,27 & 2,05 & 1,29 & 0,62 & 0,00 & 0,58 & 4,60 & 3,85 & 3,24 & 2,70 & 2,21 & 1,75 & 5,78 & 5,09 & 4,53 & 4,03 & 3,58 & 3,17 \\
\hline $10 ; 20$ & 2,73 & 2,52 & 1,80 & 1,16 & 0,56 & 0,00 & 5,14 & 4,44 & 3,86 & 3,34 & 2,87 & 2,42 & 6,41 & 5,77 & 5,24 & 4,76 & 4,33 & 3,93 \\
\hline
\end{tabular}

\begin{tabular}{|c|c|c|c|c|c|c|c|c|c|c|c|c|c|c|c|c|c|c|}
\hline $0 ; 2$ & 1,41 & 1,75 & 2,82 & 3,69 & 4,43 & 5,10 & 0,68 & 0,53 & 1,36 & 2,03 & 2,60 & 3,10 & 1,24 & 0,15 & 0,59 & 1,17 & 1,67 & 2,15 \\
\hline $2 ; 4$ & 0,43 & 0,75 & 1,77 & 2,62 & 3,37 & 4,04 & 1,66 & 0,57 & 0,24 & 0,90 & 1,48 & 2,00 & 2,35 & 1,36 & 0,64 & 0,04 & 0,47 & 0,96 \\
\hline $4 ; 8$ & 0,32 & 0,03 & 0,92 & 1,74 & 2,47 & 3,13 & 2,44 & 1,46 & 0,70 & 0,06 & 0,52 & 1,03 & 3,25 & 2,36 & 1,67 & 1,10 & 0,59 & 0,13 \\
\hline $6 ; 12$ & 0,87 & 0,60 & 0,30 & 1,08 & 1,79 & 2,44 & 3,02 & 2,12 & 1,40 & 0,78 & 0,23 & 0,28 & 3,93 & 3,11 & 2,46 & 1,90 & 1,41 & 1,00 \\
\hline $8 ; 16$ & 1,34 & 1,09 & 0,24 & 0,51 & 1,19 & 1,82 & 3,55 & 2,71 & 2,03 & 1,44 & 0,90 & 0,40 & 4,55 & 3,78 & 3,17 & 2,63 & 2,15 & 1,80 \\
\hline $10 ; 20$ & 1,74 & 1,50 & 0,69 & 0,03 & 0,69 & 1,31 & 4,00 & 3,21 & 2,56 & 1,99 & 1,47 & 0,98 & 5,07 & 4,35 & 3,77 & 3,25 & 2,79 & 2,48 \\
\hline
\end{tabular}

Note: Numbers in bold formatting indicate that there is no statistically significant difference between simple and double sampling plan in lot fraction defectives for given the maximum allowed number of defective units, and the probabilities of acceptance.

Source: Author's calculation 
The tests have shown that if the sample size in a single sampling plan is greater than the sample sizes in a double sampling plan, in vast cases can be concluded that there is statistically significant difference in lot fraction defectives between these two sampling plans. This can be easily seen in cases when the sample size in a single sampling plan is $n=300$ and the sample sizes in a double sampling plan are $n 1=n 2=50$. With the decreasing the sample sizes in a single sampling plan, the number of cases of non-rejecting the null hypothesis is increasing. In the same time, with the decreasing the sample sizes in a single sampling plan, the space of non-rejecting the null hypothesis is moved diagonally from top right corner to down left corner. That shows that the null hypothesis are not rejected for smaller the maximum allowed number of defective units in a single sampling and for bigger the maximum allowed number of defective units in a double sampling plan. If the maximum allowed numbers of defective units are observed, it can be concluded that in most cases when the maximum allowed numbers of defective units or $\mathrm{c}$ in a single sampling plan is equal to the acceptance level for the first sample or $\mathrm{cl}$ in a double sampling plan, the null hypothesis cannot be rejected. These conclusions are valid for all observed probabilities of acceptance.

\section{Discussion and Conclusion}

Using different sample sizes and maximum allowed numbers of defective units in a lot and a test for the difference in proportions, this paper indirectly analyses the probability of acceptance of lots when using a single or a double acceptance sampling plan. Directly paper analyses if there under defined conditions exist statistically significant difference between probabilities of lot fraction defectives between these two sampling plans at the same levels of probability of acceptance. If there is statistically significant difference in the probabilities of lot fraction, it can be concluded that these is statistically significant difference in the probabilities of acceptance also. That would mean that there is space for possible frauds on quality level of lots by insisting on use specified sampling plan rather than other sampling plan under some different parameters.

The conducted tests have shown that there is possibility of fraud using a single or a double sampling plan. This comes to the expression especially when the sample size in a single sampling plan is much greater than the sample sizes in a double sampling plan. Because of that to prevent possible frauds, the quality manager should keep on mind not to selected too small initial sample size in a double sampling plan. Next conclusion is that when the maximum allowed numbers of defective units in a single and in a double sampling plan are kept in the same proportion to the sample sizes, in most cases there was showed no statistically significant difference in lot fraction defectives between these two sampling plans.

The main limitation of this study is considering only six different levels of the maximum allowed number of defective units. There are far more different levels and combinations of that in practice. Because of that the results could be different as there appear in the analysis.

In further studies, we suggest using inverted approach to the problem. That would mean that the lot fraction defectives would be fixed at some levels and the difference of probabilities of acceptance in a single and in a double sampling plan would be tested. This analysis should confirm here given results and conclusions.

\section{References}

1. Dumičić, K, Bahovec, V, Kurnoga Živadinović, N. (2006), "Analysing the Shape of an OC Curve for an Acceptance Sampling Plan: A Quality Management Tool", WSEAS Transactions on Business and Economics, Vol. 3, No. 3, pp. 169-177.

2. Dumičić, K, Žmuk, B. (2011), "Impact of Applies Acceptance Sampling Plan on Decisions in Quality Management", in Zadnik Stirn, L, Žerovnik, J, Povh, J, Drobne, S, Lisec, A. (Eds), Proceedings of the 11 th International Symposium on Operational Research (SOR 2011), Slovenian Society Informatika - Section for Operational Research, Dolenjske Toplice, pp. 183-188.

3. Grant, E. L, Leavenworth, R. S. (1980). Statistical Quality Control, 5th Ed., New York: McGraw-Hill.

4. Kondić, Ž. (2004). Kvaliteta i metode poboljšanja [Quality and Improvement Methods], Čakovec: Zrinski.

5. Montgomery, D. C. (2009). Statistical Quality Control: A Modern Introduction, 6th Ed., New York: John Wiley \& Sons.

6. Montgomery, D. C, Jennings, C. L, Pfund, M. E. (2011). Managing, Controlling and Improving Quality, New Jersey: John Wiley \& Sons.

7. NIST/SEMATECH (2003), "e-Handbook of Statistical Methods", available at: http://www.itl.nist.gov/ div898/handbook/pmc/section2/pmc22.htm (3 November 2011). 
8. Starbird, S. A. (1994), "The Effect of Acceptance Sampling and Risk Aversion on the Quality Delivered by Suppliers", The Journal of the Operational Research Society, Vol. 45, No. 3, pp. 309-320.

9. Wadsworth, H. M, Stephens, K. S, Godfrey, A. B. (2002). Modern Methods for Quality Control and Improvement, 2nd Ed., New York: John Wiley \& Sons.

\section{About the authors}

Ksenija Dumičić is an Full Professor with Tenure at the Department of Statistics, Faculty of Economics \& Business, University of Zagreb. Her main research fields are sampling, statistics, business statistics, sampling for social and business surveys, sampling for opinion polling. Author can be contacted at kdumicic@efzg.hr

Berislav Žmuk is an Assistant at the Department of Statistics, Faculty of Economics \& Business, University of Zagreb. His main research field is applications of statistics in business and economy. He is a doctoral student at Faculty of Economics \& Business, University of Zagreb. Author can be contacted at bzmuk@efzg.hr 